\title{
Biliary lipid compositions in cholestatic diseases of infancy
}

\author{
Y TAZAWA, M YAMADA, M NAKAGAWA, T KONNO, AND K TADA \\ Department of Pediatrics, Tohoku University School of Medicine, Sendai, Japan
}

SUMMARY Biliary lipid compositions in infants with cholestasis were analysed. Bile acid and phospholipid values were appreciably lower in infants with idiopathic neonatal hepatitis syndrome or corrected biliary atresia than in control infants. Cholesterol values were not, however, notably lower in infants with cholestasis. When biliary lipid components were determined in terms of molar percent, bile acid values were considerably lower in infants with cholestasis than in controls, and cholesterol and phospholipids were appreciably higher, as was the lithogenic index.

Obstructive jaundice in early infancy is usually caused by biliary atresia or idiopathic neonatal hepatitis syndrome, but its aetiology remains unknown. Although fetal or neonatal derangement of bile acid metabolism has been implicated, ${ }^{1}$ analysis of bile acids ${ }^{2-6}$ has not yet provided the necessary proof. Hydrophobic substances in bile are rendered soluble by mixed micelle formed by bile acids and lecithin and the quality and quantity of the micelle, which are governed by several factors including bile acid concentrations, determine the solubility of these hydrophobic substances. ${ }^{7}$ It is well known that biliary lipid concentrations are altered in some conditions such as cholesterol gallstone or cholestasis ${ }^{89}$ and it is possible that this alteration is associated with the pathogenesis of cholestatic disease in early infancy. There have been few reports, however, on the biliary lipid composition in children with cholestasis except those on bile acid concentrations..$^{51011}$ We examined biliary lipid compositions in infants with intrahepatic cholestasis and in those who underwent hepatoportojejunostomy because of extrahepatic biliary atresia.

\section{Material and methods}

Patients. Twelve infants with idiopathic neonatal hepatitis syndrome (INHS), mean age 13.3 weeks; 10 infants with biliary atresia (BA), mean age 20.3 weeks (who had undergone double Rou-Y hepatoportojejunostomy (Kasai's procedure) at 7-8 weeks of age); and 12 control infants, mean age 21.0 weeks, without hepatic or intestinal disease were studied. Both the INHS and BA infants had high serum bilirubin concentrations of over $(20.5$ $\mu \mathrm{mol} / \mathrm{l})(1.2 \mathrm{mg} / 100 \mathrm{ml})$ and there were no notable differences between these two groups in routine liver function tests including serum bilirubin and serum transaminase values. In addition, we subsequently analysed for comparative study specimens taken from three infants with INHS and from three with BA.

Upper intestinal aspiration. Duodenal aspiration without exogenous stimulation was used to obtain bile specimens from INHS and control infants who had been fasted. Specimens were also taken from the jejunal stoma made in the abdominal wall of fasted infants with BA. These samples were frozen immediately until analysis. In patients with severe cholestasis an almost acholic juice was obtained. We discarded duodenal juice in which the bile acid concentration was below $0.5 \mu \mathrm{mol} / \mathrm{ml}$.

Bile acid assay. Bile juice $(0.2 \mathrm{ml})$ was mixed with ethanol $(4.8 \mathrm{ml})$ and left overnight at room temperature. After centrifugation at $3000 \mathrm{rpm}$ for $10 \mathrm{~min}$, $0.5 \mathrm{ml}$ of supernatant was then transferred and brought up to a volume of $4.0 \mathrm{ml}$ by the addition of ethanol. One $\mathrm{ml}$ of $1 . \mathrm{OM}$ sodium hydroxide was then added to the solution. An equal volume of hexane was used for removing cholesterol and other lipid contaminations. The pooled hexane fraction was used for the cholesterol assay described below. The remainder was then washed four times with hexane, ethanol was eliminated in a water bath, and 
$4.0 \mathrm{ml}$ of $1 . \mathrm{OM}$ sodium hydroxide was added. Alkaline hydrolysis, extraction of free bile acids, and gas liquid chromatography using a $0.2 \%$ Poly-I 110 column were then performed as reported. ${ }^{6}$

Cholesterol and phospholipid assay. The hexane fractions obtained during bile acid analysis were used for cholesterol assay according to the method of Zlatkis et al. using o-phthalaldehyde. ${ }^{12}$ Quantitative values of cholesterol were determined by colorimetric procedure at $550 \mathrm{~nm}$. Bile phospholipid extraction was based on the method of Folch et $a .^{13}$ using a chloroform methanol mixture (2:1 vol/vol). The phospholipid concentration was measured by the method of Fiske and Subbarow. ${ }^{14}$

Calculation of molar percentages. The biliary total bile acid, cholesterol, and phospholipid concentrations were calculated in terms of molar percent (mol \%) of total biliary lipid compositions and plotted as a single point on triangular coordinates by a standard method. ${ }^{8}$ The lithogenic index, a quantitative representation of the cholesterol saturation of the bile by a single number that accounts for all three biliary lipids, was calculated using the equation of Thomas and Hoffman. ${ }^{15}$ The index is defined as the ratio of cholesterol actually present in the maximal amount that would be soluble at the phospholipid: bile acid ratio of the sample. When multiplied by 100 , this index is identical to the percent saturation that has been used by other workers. ${ }^{16}$

\section{Results}

Biliary lipid compositions in INHS and BA infants and controls. Infants with INHS and corrected BA had lower mean concentrations of total bile acid, cholesterol, and phospholipid than the control infants, but these values were significant only for total bile acid and phospholipid-bile acid; mean (SD), $4 \cdot 4$ (4.7) $\mu \mathrm{mol} / \mathrm{lml}$ and $19 \cdot 11(16 \cdot 51) \mu \mathrm{mol} / \mathrm{ml}$; $\mathrm{P}<.001$ and phospholipid, mean (SD) $1.56(1.4)$ $\mu \mathrm{mol} / \mathrm{ml}$ and $3.24 \quad(1.14) \mu \mathrm{mol} / \mathrm{ml}, \quad P<0.02$ (Table 1). Total bile acid values were less than $2.0 \mu \mathrm{mol} / \mathrm{ml}$ in 7 of 22 infants with cholestasis (Table 1). Cholate was the predominant bile acid and the ratio of cholate to chenodeoxycholate was, mean (SD) $3.14(1.8)$ in infants with cholestasis and $3 \cdot 12(2 \cdot 33)$ in control infants (Table 1). Small amounts of lithocholate, deoxycholate, and ursodeoxycholate were occasionally found.

The mol \% values were significantly higher in the cholestatic group than in the control group for cholesterol and phospholipid-cholesterol, mean (SD) $9.3(3.0) \%$ and $2.8(1.6) \%, \mathrm{P}<0.001$; and phospholipid, mean (SD) $24.6(9.9) \%$ and 16.6 (8.5) $\%, P<0.05$. The mol $\%$ of total bile acid was, however, significantly lower in the cholestatic children than in the controls-mean (SD) 65.4 (9.4) $\%$ and 80.3 (9.4) \%, P $<0.001$ (Fig. 1).

The cholesterol saturation in the control infants was less than 1.0 and was related neither to age nor to bile acid concentrations. Cholesterol saturation was higher in cholestatic infants than in controlsmean (SD), $1.06(0.51)$ and $0.3(0.16), \mathrm{P}<0.001$. In the INHS infants cholesterol saturation was significantly related to age $(\mathrm{P}<0.05)$ but this was not the case in infants with BA (Figs. 2 and 3). We did not find any relation between cholesterol saturation and serum direct bilirubin values.

Biliary lipid compositions in INHS and BA groups. The INHS group showed higher values of mol \% cholesterol and cholesterol saturation than the BA group-mol $\%$ cholesterol, mean (SD) $10 \cdot 3$ (3.3) \% and $8.4(2.6) \%$ and cholesterol saturation, mean (SD) $1.28(0.64)$ and $0.88(0.28)$ (Fig. 1). No significant differences were found, however, between the two groups. The cholate: chenodeoxycholate ratio in the INHS infants was lower than that of the BA group-mean (SD), $2.28(1.72)$ and 3.43 $(1 \cdot 59)$ respectively, but no significant difference was found (Table 1).

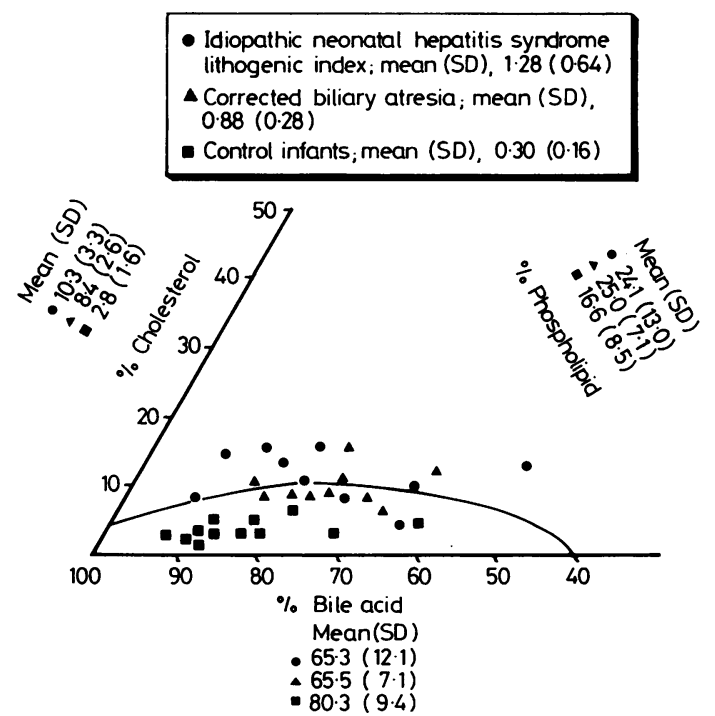

Fig. 1 Biliary lipid composition plotted on triangular coordinates. Values under the curve line are unsaturated with cholesterol, those above the line are supersaturated. 


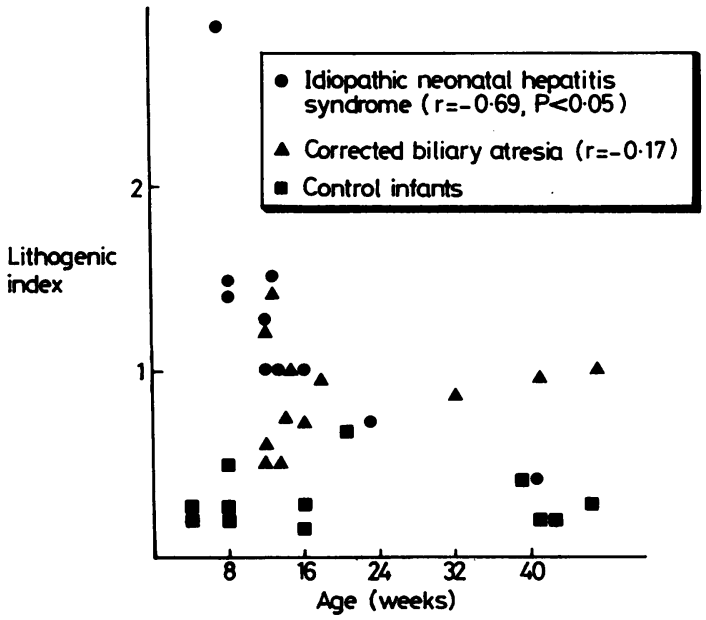

Fig. 2 Relation between lithogenic index and age in control infants and infants with cholestasis

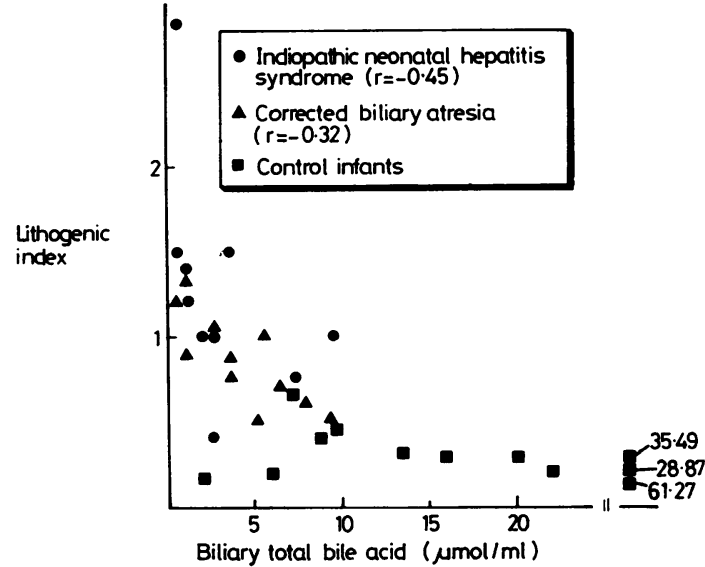

Fig. 3 Relation between lithogenic index and total bile acid in control infants and infants with cholestasis

Table 1 Biliary lipid compositions in infants with cholestasis (I)

\begin{tabular}{|c|c|c|c|c|c|c|c|c|}
\hline $\begin{array}{l}\text { Case } \\
\text { No }\end{array}$ & Sex & $\begin{array}{l}\text { Age } \\
\text { (weeks) }\end{array}$ & $\begin{array}{l}T B A \\
(\mu \mathrm{mol} / \mathrm{ml})\end{array}$ & $\begin{array}{l}C \\
(\mu \mathrm{mol} / \mathrm{ml})\end{array}$ & $\begin{array}{l}C D C \\
(\mu \mathrm{mol} / \mathrm{ml})\end{array}$ & $C: C D C$ & $\begin{array}{l}\text { CHo } \\
(\mu \mathrm{mol} / \mathrm{ml})\end{array}$ & $\begin{array}{l}P L \\
(\mu \mathrm{mol} / \mathrm{ml})\end{array}$ \\
\hline \multicolumn{9}{|c|}{ Corrected biliary atresia $(n=12)$} \\
\hline 1 & $\mathbf{F}$ & 12 & $7 \cdot 77^{*}$ & $5 \cdot 57$ & 1.85 & $3 \cdot 01$ & 0.77 & $4 \cdot 58$ \\
\hline 2 & $\mathbf{F}$ & 12 & 0.64 & 0.47 & 0.17 & $2 \cdot 76$ & 0.12 & 0.50 \\
\hline 3 & $\mathbf{F}$ & 12 & $9 \cdot 25^{*}$ & $6 \cdot 90$ & $2 \cdot 00$ & $3 \cdot 45$ & 0.65 & 3.01 \\
\hline 4 & $\mathbf{F}$ & 13 & 5.07 & $4 \cdot 27$ & 0.80 & $5 \cdot 33$ & 0.38 & 1.91 \\
\hline 5 & $\mathbf{F}$ & 13 & 1.07 & 0.87 & 0.20 & $4 \cdot 35$ & 0.25 & 0.38 \\
\hline 6 & $\mathbf{F}$ & 14 & $3 \cdot 72$ & $3 \cdot 22$ & 0.50 & 6.44 & 0.40 & 1.05 \\
\hline 7 & $\mathbf{F}$ & 14 & $5 \cdot 72$ & $4 \cdot 77$ & 0.95 & 5.02 & 0.75 & $1 \cdot 21$ \\
\hline 8 & $\mathbf{F}$ & 14 & $6 \cdot 59^{*}$ & $3 \cdot 92$ & $2 \cdot 27$ & $1 \cdot 72$ & 0.75 & $3 \cdot 28$ \\
\hline 9 & $\mathbf{F}$ & 16 & 0.82 & 0.50 & 0.32 & 1.56 & 0.11 & 0.25 \\
\hline 10 & $\mathbf{M}$ & 18 & 3.44 & 2.47 & 0.97 & $2 \cdot 54$ & 0.46 & $1 \cdot 31$ \\
\hline 11 & $\mathbf{M}$ & 32 & $21 \cdot 20^{*}$ & $16 \cdot 85$ & 3.95 & $4 \cdot 26$ & 2.53 & $4 \cdot 58$ \\
\hline 12 & $\mathbf{M}$ & 41 & $2 \cdot 47^{*}$ & $1 \cdot 45$ & 0.25 & $5 \cdot 80$ & 0.39 & 0.98 \\
\hline $\begin{array}{l}\text { Mean } \\
\text { (SD) }\end{array}$ & & $\begin{array}{c}20 \\
(12)\end{array}$ & $\begin{array}{c}5 \cdot 64 \\
(5 \cdot 64)\end{array}$ & $\begin{array}{c}4 \cdot 27 \\
(4 \cdot 46)\end{array}$ & $\begin{array}{c}1 \cdot 18 \\
(1 \cdot 13)\end{array}$ & $\begin{array}{c}3 \cdot 85 \\
(1 \cdot 59)\end{array}$ & $\begin{array}{c}0.63 \\
(0.64)\end{array}$ & $\begin{array}{c}1.92 \\
(1.56)\end{array}$ \\
\hline \multicolumn{9}{|c|}{ Idiopathic neonatal hepatitis syndrome $(n=10)$} \\
\hline 13 & $\mathbf{M}$ & 7 & 0.70 & $\mathbf{0} \cdot 30$ & 0.40 & 0.75 & $0 \cdot 20$ & 0.86 \\
\hline 14 & $\mathbf{M}$ & 8 & 1.05 & 0.35 & 0.70 & 0.50 & 0.23 & 0.34 \\
\hline 15 & $\mathbf{M}$ & 8 & $2 \cdot 57$ & 2.05 & 0.52 & 3.94 & 0.51 & 0.56 \\
\hline 16 & $\mathbf{F}$ & 12 & 1.00 & 0.60 & 0.40 & $1 \cdot 50$ & $0 \cdot 18$ & 0.25 \\
\hline 17 & $\mathbf{M}$ & 12 & $9 \cdot 32$ & $7 \cdot 27$ & 2.05 & $3 \cdot 54$ & $1 \cdot 39$ & $2 \cdot 68$ \\
\hline 18 & $\mathbf{M}$ & 13 & $0 \cdot 70$ & 0.60 & 0.10 & 6.00 & $0 \cdot 12$ & 0.09 \\
\hline 19 & $\mathbf{M}$ & 13 & $2 \cdot 82$ & $1 \cdot 70$ & $1 \cdot 12$ & $1 \cdot 51$ & 0.28 & 0.27 \\
\hline 20 & $\mathbf{M}$ & 16 & $2 \cdot 22$ & $1 \cdot 57$ & 0.65 & 2.41 & 0.36 & 1.42 \\
\hline 21 & $\mathbf{M}$ & 23 & $7 \cdot 32$ & $4 \cdot 10$ & $3 \cdot 22$ & $1 \cdot 27$ & 0.88 & $3 \cdot 41$ \\
\hline 22 & $\mathbf{M}$ & 41 & $2 \cdot 42$ & $1 \cdot 42$ & $1 \cdot 00$ & 1.42 & $0 \cdot 15$ & $1 \cdot 48$ \\
\hline $\begin{array}{l}\text { Mean } \\
\text { (SD) }\end{array}$ & & $\begin{array}{c}13 \\
(11)\end{array}$ & $\begin{array}{c}3.01 \\
(2.94)\end{array}$ & $\begin{array}{c}2 \cdot 05 \\
(2 \cdot 28)\end{array}$ & $\begin{array}{c}1 \cdot 01 \\
(0.94)\end{array}$ & $\begin{array}{c}2 \cdot 28 \\
(1 \cdot 74)\end{array}$ & $\begin{array}{c}0.43 \\
(0.40)\end{array}$ & $\begin{array}{c}1 \cdot 13 \\
(1 \cdot 12)\end{array}$ \\
\hline \multicolumn{9}{|c|}{ Cholestatic infants $(n=22)$} \\
\hline Mean & & & $\begin{array}{c}4 \cdot 44 \dagger \\
(4 \cdot 70)\end{array}$ & $\begin{array}{c}3 \cdot 23 \dagger \\
(3 \cdot 71)\end{array}$ & $\begin{array}{c}1 \cdot 10 \ddagger \\
(1 \cdot 03)\end{array}$ & $\begin{array}{c}3 \cdot 14 \\
(1 \cdot 80)\end{array}$ & $\begin{array}{c}0.53 \\
(0.54)\end{array}$ & $\begin{array}{c}1 \cdot 568 \\
(1 \cdot 40)\end{array}$ \\
\hline \multicolumn{9}{|c|}{ Control infants $(n=12)$} \\
\hline $\begin{array}{l}\text { Mean } \\
\text { (SD) }\end{array}$ & & & $\begin{array}{c}19 \cdot 11 \dagger \\
(16 \cdot 51)\end{array}$ & $\begin{array}{r}13 \cdot 22 \dagger \\
(10 \cdot 21)\end{array}$ & $\begin{array}{r}5 \cdot 89 \ddagger \\
(7 \cdot 08)\end{array}$ & $\begin{array}{l}3 \cdot 12 \\
(2 \cdot 33)\end{array}$ & $\begin{array}{l}0.55 \\
(0 \cdot 28)\end{array}$ & $\begin{array}{l}3 \cdot 098 \\
(1 \cdot 88)\end{array}$ \\
\hline
\end{tabular}

TBA = total bile acid; $\mathbf{C}=$ cholate $\mathbf{C D C}=$ chenodeoxycholate; $\mathbf{C}: \mathbf{C D C}=$ ratio of cholate to chenodeoxycholate; $\mathbf{C H o}=$ cholesterol .

$\mathbf{P L}=$ phospholipid.* Including values of deoxycholate, lithocholate, or ursodeoxycholate; $\nmid \mathbf{P}<0.001 ; \ddagger \mathbf{P}<0.005 ; \S \mathbf{P}<0.02$. 
Table 2 Biliary lipid compositions in the period after cholestatic disease

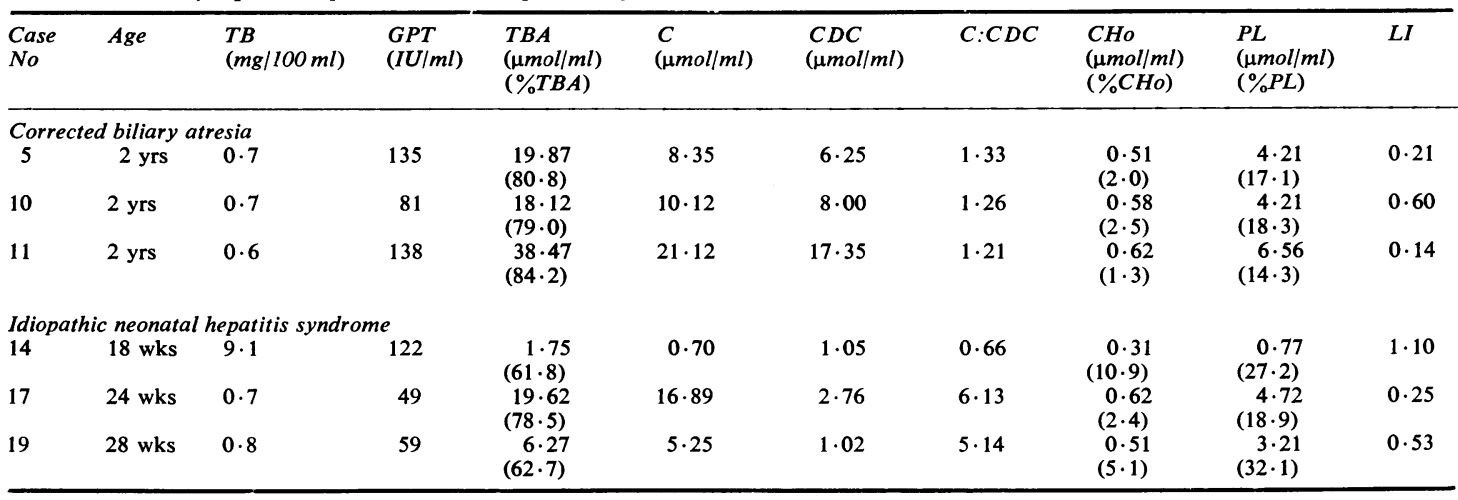

$\mathrm{TB}=$ serum total bilirubin; $\mathrm{GPT}=$ serum glutamic pyruvic transaminase; $\mathrm{TBA}=$ total bile acids; $\mathrm{C}=$ cholate; $\mathrm{CDC}=$ chenodeoxycholate $\mathrm{C}: \mathrm{CDC}=$ ratio of cholate to chenodeoxycholate; $\mathrm{CHO}=$ cholesterol; $\mathbf{P L}=$ phospholipid; LI $=$ lithogenic index; $\% \mathrm{TBA}=$ molar percent of total bile acids; $\% \mathrm{CHo}=$ molar percent of cholesterol; $\% \mathrm{PL}=$ molar percent of phospholipid.

Biliary lipid concentrations subsequent to cholestasis. Six children-three with corrected BA and three with INHS-were studied subsequently for comparison. In five of the children (3 with corrected BA and 2 with INHS) no abnormalities in biliary lipid compositions were found but in one child with INHS, who had persistent jaundice and liver dysfunction, biliary lipid compositions were still abnormal 16 weeks after the disease (Table 2).

\section{Discussion}

Bile acids are important for micelle formation in bile. The micelle formation plays a part in lipid absorption and in rendering soluble, hydrophobic substances such as cholesterol. It is well known that supersaturated cholesterol in bile occasionally forms cholesterol crystals which later proceed to gallstone formation, ${ }^{8}$ but it has never been reported that cholesterol crystal, liquid crystal, or other hydrophobic substances that are usually made soluble by micelle, affect the small calibre biliary system of fetuses or neonates.

It is presumed that in cholestasis the rate of bile acid excretion from the liver to the biliary system decreases and that biliary cholesterol saturation increases. ${ }^{17}$ Physiological cholestasis has been reported in the neonatal period, ${ }^{18} 19$ and it may be that some substance in bile such as bile acid, cholesterol crystal, or lysolecithin that has a toxic effect on the biliary system, initiates or promotes pathological cholestasis.

There is little information on biliary lipid compositions in children, except for bile acids, ${ }^{5} 101120-22$ but in adults with chronic cholestatic liver disease, altered biliary lipid compositions-particularly cholesterol-saturation have been reported. ${ }^{9}$ Our findings in cholestatic children were similar but it is possible that cholesterol supersaturation in bile does not similarly affect the hepatobiliary systems of infants and adults. Although extrahepatic biliary obstruction was relieved and bile drainage effected in the BA infants, the lithogenic index remained high. With increased age, however, the index decreased. This suggests that other than intrahepatic disease there was no persistent abnormality in biliary cholesterol saturation such as an abnormal intrahepatic biliary tree or hepatocellular injury. ${ }^{11}$ Although the biliary" lipid compositions of control infants in this study showed lower mol \% cholesterol and cholesterol saturation than other reports, ${ }^{2021}$ this may be explained by racial differences. ${ }^{23}$

Supported by a grant from the Ministry of Education, Science, and Culture of Japan.

\section{References}

1 Landing BH. Considerations of the pathogenesis of neonatal hepatitis, biliary atresia and choledochal cystthe concept of infantile obstructive cholangiography. Prog Pediatr Surg 1974;6:113-39.

2 Makino I, Sjövall J, Norman A, Strandvik B. Excretion of $3 \beta$-hydroxy-5-cholenoic and $3 \alpha$-hydroxy-5 $\alpha$-cholenoic acids in urine of infants with biliary atresia. FEBS Lett $1971 ; 15: 161-4$.

3 Norman A, Strandvik B. Metabolism of lithocholic acid$24-{ }^{14} \mathrm{C}$ in extrahepatic biliary atresia. Acta Paediatr Scand 1974;63:92-6.

4 Javitt NB, Keating JP, Grand RJ, Harris RC. Serum bile acid patterns in neonatal hepatitis and extrahepatic biliary atresia. J Pediatr 1977;90:735-49. 
5 Délèze G, Paumgartner GD. Bile acids in serum and bile of infants with cholestatic syndromes. Helv Paediatr Acta 1977;32:29-38.

6 Tazawa Y, Konno T. Urinary monohydroxy bile acids in young infants with obstructive jaundice. Acta Paediatr Scand 1982;71:91-5.

7 Heaton KW. Bile salts in health and disease. Edinburgh \& London: Churchill Livingstone, 1972;24-41.

8 Admirand WH, Small DM. The physicochemical basis of cholesterol gallstone formation in man. J Clin Invest $1968 ; 47: 1043-52$.

9 Kesäniemi YA, Salaspuro MP, Vuoristo M, Miettinen TA. Biliary lipid secretion in chronic cholestatic liver disease. Gut 1982;23:931-8.

10 Stiehl A, Becker M, Czygan P, et al. Bile acids and their sulphated and glucuronidated derivatives in bile, plasma and urine of children with intrahepatic cholestasis: effects of phenobarbital treatment. Eur J Clin Invest 1980;10:307-16.

11 Lilly JR, Javitt NB. Biliary lipid excretion after hepatic portoenterostomy. Ann Surg 1976;184:369-75.

12 Zlatkis A, Zak B. Study of a new cholesterol reagent. Anal Biochem 1969;29:143-8.

13 Folch J, Lees M, Sloane-Stanley GH. A simple method for the isolation and purification of total lipids from animal tissues. $J$ Biol Chem 1957;226:497-509.

14 Fiske $\mathrm{CH}$, Subbarow Y. The colorimetric determination of phosphorus. J Biol Chem $1925 ; 66: 375-400$.

15 Thomas PJ, Hofmann AF. A simple calculation of the lithogenic index of bile: expressing biliary lipid composition on rectoangular coordinates (letter). Gastroentero$\log y 1973 ; 65: 698-700$.
16 Redinger RN, Small DM. Bile composition, bile salt metabolism and gallstones. Arch Intern Med 1972;130: 618-30.

17 Wagner CI, Trotman BW, Soloway RD. Kinetic analysis of biliary lipid excretion in man and dog. $J$ Clin Invest 1976;57:473-7.

18 Lester R. Physiologic cholestasis. Gastroenterology $1980 ; 78: 864-5$.

19 Suchy FU, Balistreri WF, Heubi JE, Searcy JE, Levin RS. Physiologic cholestasis: elevation of the primary serum bile acid concentrations in normal infants. Gastroentero$\log y 1981 ; 80$ : $1037-41$.

20 Heubi JE, Soloway RD, Balistreri WF. Biliary lipid composition in healthy and diseased infants, children, and young adults. Gastroenterology 1982;82:1295-9.

${ }^{21}$ Von Bergmann J, Von Bergmann K, Hadorn B, Paumgartner G. Biliary lipid composition in early childhood. Clin Chim Acta 1975;64:241-6.

22 Roy CC, Weber AM, Morin CL, et al. Abnormal biliary lipid composition in cystic fibrosis. Effect of pancreatic enzymes. N Eng J Med 1977;2y7:1301-5.

${ }^{23}$ Heaton KW. The epidemiology of gallstones and suggested aetiology. Clin Gastroenterol 1973;2:67-83.

Correspondence to Dr Y Tazawa, Tohoku University School of Medicine, Department of Paediatrics, 1-1 Seiryomachi, Sendai 980, Japan.

Received 21 June 1983 